\title{
Trigeminal root and ganglion injections using phenol in glycerine for the relief of trigeminal neuralgia
}

\author{
ANTONY JEFFERSON
}

\author{
From the Department of Neurological Surgery, Royal Infirmary, Sheffield
}

By no means all those responsible for the treatment of severe trigeminal neuralgia view trigeminal root or ganglion injections with favour. Their objections are based on the difficulty of precisely placing the needle point (with consequent uncertainty of a successful result) and on real or imagined dangers.

The results of trigeminal root and ganglion injections described here have been obtained using phenol dissolved in glycerine. This agent was introduced by Maher (1955) for injection in the spinal canal, and its use relieved pain with only partial sensory loss. To control trigeminal neuralgia without producing total numbness of the affected areas of the face would be of undoubted advantage to the patient.

Those who have used the Härtel approach (Härtel, 1912) for intracranial trigeminal injections know that the needle may enter Meckel's cave without impaling the third division of the trigeminal nerve, or its ganglion, or its posterior root. Under these circumstances small quantities of alcohol, e.g., $<0.2 \mathrm{ml}$., may prove ineffective. By using Maher's agent with the patient in the upright position it was envisaged that the heavy solution of phenol in glycerine could be made to flow over the ganglion and to bathe the posterior root within Meckel's cave. In this way it was hoped to create a satisfactory neurological lesion without having to place the needle point as precisely as when alcohol is the medium to be injected.

The extent to which reality has accorded with these hopes is set out below.

\section{MATERIAL}

Up to the end of June 1962 a total of 37 patients had received injections. In seven patients there was a failure in technique, i.e., presumably improper placing of the needle point, so that 'immediate' re-injection for pain which was never adequately controlled or which recurred within one week was necessary.

All patients with relatively mild pain were given a trial of treatment with mephenesin carbamate (King,
1958). Only when this proved ineffective was an injection carried out. The pathological cause for the pain was true trigeminal neuralgia in 32, post-herpetic neuralgia in two, and cancer of the mouth in three patients.

The material most commonly employed was phenol $1: 20$ in glycerine; the mean volume injected in these procedures was just less than $0.5 \mathrm{ml}$. Phenol $1: 30$ in glycerine was used on four occasions, but it appeared to produce slightly less sensory loss than was desired. Phenol 1:25 in glycerine plus silver nitrate $0.64 \mathrm{mg}$. per $\mathrm{ml}$. was used six times; on these occasions the sensory loss was rather denser than required. The injection material was usually freshly prepared; it was rejected if it was more than six days old. Under sterile conditions, the phenol was added to glycerine which had been previously sterilized by dry heat, and the solution was stored in a rubber-capped dark glass bottle and kept in a refrigerator until required.

\section{TECHNIQUE}

Observations made in the post-mortem room on six cadavers had shown that the needle lay at the junction of Meckel's cave and the pontine cistern when its point was 5.0 to $11.0 \mathrm{~mm}$. posterior to the profile of the clivus as seen in a lateral radiograph. Figure 1 shows a typical example of this position. Further studies revealed that when a needle was inserted by the Härtel approach and traversed the lateral third of the foramen ovale it might damage the arachnoid and the dura on the lateral wall of Meckel's cave. The needle point did not penetrate into the middle fossa and the defect in the dura was not usually visible to the naked eye; however, fluid injected via the needle into Meckel's cave could under these circumstances escape into the middle fossa. Figure 2 shows the appearance in the lateral projection of a needle inserted to the current target point. Figure 3 illustrates the appearance of the needle as seen in the submento-vertical view.

A $9.0 \mathrm{~cm}$. a 19 S.W.G. needle with a relatively short bevel was used. The capacity of such needles, when glycerine has been previously injected through them, is roughly 0.02 to $0.03 \mathrm{ml}$. Initially, ordinary syringes of $1.0 \mathrm{ml}$. or sometimes $2.0 \mathrm{ml}$. capacity were used, but more recently tuberculin syringes of $1.0 \mathrm{ml}$. capacity have been regularly employed.

All the patients were admitted to hospital and were discharged 18 to 48 hours after the completion of a 




FIG. 1. True lateral radiograph obtained in a cadaver after the vault of the skull and the brain had been removed. The needle point has been adjusted so that it lies at the posterior exit of Meckel's cave.

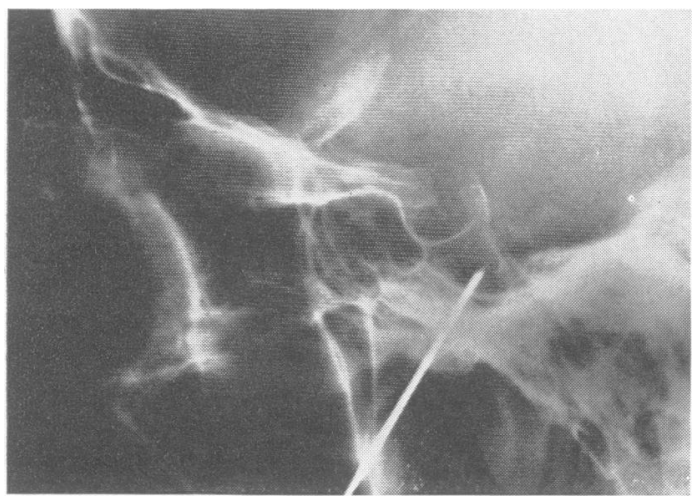

FIG. 2. True lateral radiograph to illustrate the depth to which the needle is inserted.



FIG. 3. Submento-vertical radiograph to illustrate needle passing through the centre of the foramen ovale. satisfactory injection. They were premedicated with Omnopon, $20 \mathrm{mg}$., and Scopolamime, $0.40 \mathrm{mg}$., or with an appropriate smaller fraction of this dose if they were old or under weight.

The skin of the face was cleansed with iodine and alcohol and local anaesthetic was injected at the point of entry of the needle and relatively superficially in the cheek. The relative painlessness with which the needle can be introduced into Meckel's cave in the premedicated patient is a surprising but readily verifiable fact. Thus, whenever possible, the needle was inserted through the foramen ovale and into Meckel's cave without injecting further



FIG. 4. When the position of the needle has been checked and adjusted under radiological control, the patient is sat up so that the needle is roughly vertical. Phenol in glycerine is injected in small increments using a tuberculin syringe.

local anaesthetic. Such injections might have blocked conduction in the trigeminal nerve and made it difficult to assess the development of the partial sensory loss which it was hoped to produce by means of the phenol solution. In four patients the passage of the needle into its final position caused a sensory loss, presumably by mechanical damage to nerve fibres against which it was lying.

The patient lay supine during the insertion of the needle, and was then placed in the upright position with the neck well flexed so that the needle lay vertically (Fig. 4). All injections were made with radiographic control; the two projections employed were true lateral (with the film 
on the side of the injection) and submento-vertical. Usually the exposures were made after the needle had been felt to pass through the foramen ovale. However, if there was difficulty in entering the foramen and the patient was experiencing pain, radiographs were exposed in order that the needle might be correctly aligned. Twice the needle failed to enter the foramen. Initially, the tip of the needle was adjusted until it lay precisely opposite, or not more than 2.0 to $3.0 \mathrm{~mm}$. anterior, to the profile of the clivus. More recently the needle point has been aimed to lie roughly $5.0 \mathrm{~mm}$. anterior to the clivus. Cerebrospinal fluid escaped from the needle in roughly half the injections. This phenomenon was no contraindication to proceeding with the injection provided that the position of the needle was checked radiographically. The escape of cerebrospinal fluid merely signalled that the needle point lay in the subarachnoid space in Meckel's cave.

The phenol injection was carried out in small increments. Currently an initial injection of 0.15 to $0.20 \mathrm{ml}$. is made, and increments of 0.05 to $0.10 \mathrm{ml}$. are added until the desired result is obtained. Sensory testing was carried out before insertion of the needle, after insertion of the needle to the target point, and after each increment of the injection.

To date, the patient has been kept sitting upright for 20-30 minutes after the injection is completed, with the needle undisturbed for most if not all of this time. When it was desired to deepen the sensory loss in the lower part of the face without increasing the loss in the upper part of the face, the needle was withdrawn 3.0 to $7.0 \mathrm{~mm}$. from its initial position before further increments of phenol were made.

The behaviour of a radio-opaque medium (Myodil) injected by these techniques was investigated initially in the necropsy room and subsequently in vivo immediately after the conclusion of the phenol injection.

\section{RESULTS}

The first injection was performed in December 1959, and the average period of follow-up to date is $12 \frac{1}{2}$ months.

The two smaller groups of patients will be discussed first. In both patients with post-herpetic neuralgia the results were not permanently favourable, although there was an initial transient phase of apparent success. It is worthy of comment that the injections did not appear to make the patients worse. Both patients were handicapped by dissatisfaction with their current lot in life. Probably neither of them was in acute pain following the injections, although they were by no means free of complaints, including complaints of pain. From a limited experience with the three patients with carcinoma of the mouth and tongue it seems probable that in such a situation a dense sensory loss is required in order effectively to control pain. The facts of movement and secondary infection in the painful area (to- gether with possible involvement of cervical nerve territory by the carcinoma) were probably responsible for making a dense sensory loss necessary. It is doubtful whether deliberate partial trigeminal denervation has much place in the relief of pain due to carcinoma in this area.

For true trigeminal neuralgia this method appears to be extremely safe and remarkably free from complications. Out of a total of 46 injections only one patient has had any associated cranial nerve lesion. This was a man aged $79(60 / 934)$ who had a transient sixth nerve palsy which was evident for six hours after the injection of $0.6 \mathrm{ml}$. of phenol $1: 20$ glycerine and resolved completely. Some patients have experienced paraesthesiae after the injection but in none in this group have these been severe. None of these patients has been driven to receive further treatment either at my hands or elsewhere because of the severity of the unpleasant sensations. Thus, there have been no cases of anaesthesia dolorosa. No patients have developed corneal ulcers. One patient, who had a considerable sensory loss, experienced rather troublesome ulceration of the ala nasae. It is impossible to report accurately on the frequency of post-injection herpes, because I have not seen it but from the patients' reports there is reason to believe that some of them experienced it.

Sixty per cent of the patients never had a detectable masticatory weakness. In the affected patients the muscles of mastication were again functioning normally when they were re-examined three to four months after the injection.

The quality of the sensory loss in the successful injections is set out in Table I. If the density of the

\section{TABLE I}

CASES GROUPED ACCORDING TO AMOUNT OF SENSORY LOSS CAUSED BY INJECTION

\begin{tabular}{|c|c|c|}
\hline Category & Degree of Sensory Loss & No. of Patients \\
\hline $\mathbf{A}$ & Negligible to minor & 12 \\
\hline B & $\begin{array}{l}\text { Pronounced, but usually partly 'dis- } \\
\text { sociated' involving } 1 \text { or } 2 \text { divisions; } \\
\text { corneal reflex preserved }\end{array}$ & 17 \\
\hline C & $\begin{array}{l}\text { Pronounced (usually with less evidence } \\
\text { of 'dissociation') involving } 2 \text { or } 3 \\
\text { divisions; corneal reflex abolished }\end{array}$ & 8 \\
\hline
\end{tabular}

sensory loss is related to the possibility of recurrence it is found that the less the sensory loss the greater the possibility of recurrent pain ( $c f$. , Härtel, 1935). Of the 12 patients with 'negligible to minor' sensory loss, pain recurred in four: recurrence within two months, controlled for the past 15 months with Mephenesin; a mild recurrence at four months, not requiring treatment; a mild recurrence at eight months responded to infraorbital nerve injection 
with alcohol; recurrence at 14 months required re-injection of root and ganglion with phenol.

Of those patients in group $B$ in Table $I$, six experienced recurrences of pain: recurrence at six months with pain from carcinoma of the tongue, treated with alcohol injection of the trigeminal ganglion; recurrence at 12 months required reinjection of the root and ganglion with phenol. Recurrence at 12 months responded to Mephenesin. Recurrence at 16 months required reinjection of the root and ganglion with phenol. Mild recurrence at 19 months was treated with alcohol injection of the infraorbital nerve. Recurrence at $\mathbf{2 1}$ months required re-injection of the root and ganglion with phenol.

Among those patients in group $\mathrm{C}$ in Table I only one recurrence was noted four months after the injection. It was mild and responded to Mephenesin.

There was no obvious correlation between the volume of injected material and the degree of sensory loss. Table II indicates the relationship between

\section{TABLE II}

RELATIONSHIP BETWEEN ESCAPE OF CEREBROSPINAL FLUID DURING INJECTION AND QUALITY OF SENSORY LOSS.

\begin{tabular}{ccccc}
$\begin{array}{c}\text { Category of } \\
\text { Sensory Loss }\end{array}$ & $\begin{array}{c}\text { Numbers of } \\
\text { Injections }\end{array}$ & \multicolumn{2}{l}{$\begin{array}{l}\text { Escape of Cerebrospinal Fluid from } \\
\text { Needle during Injection }\end{array}$} \\
\cline { 3 - 5 } & & Present & Absent & No Data \\
\hline A & 17 & 3 & 13 & 1 \\
B & 21 & 10 & 10 & 1 \\
C & 8 & 3 & 3 & 2
\end{tabular}

${ }^{1}$ All injections, including repeated injection.

the quality of sensory loss and the escape of cerebrospinal fluid from the needle during the injection. It seems likely that when cerebrospinal fluid escapes there is a good chance of the injection material successfully bathing the posterior root and the ganglion. However, it is known (Fig. 6) that the needle point may be enmeshed in posterior root filaments and cerebrospinal fluid may not escape to signal the satisfactory position of the needle.

The case histories of four patients provide detailed examples of the different categories in the series.

A woman, aged 60, had severe right trigeminal neuralgia of six months' duration, involving the second and third divisions. At the injection, radiographs showed the needle point $5 \mathrm{~mm}$. anterior to the clivus. The needle was inserted $4 \mathrm{~mm}$. deeper, and the patient sat erect. The total quantity injected was $0.40 \mathrm{ml}$. phenol $1: 20$ in glycerine. The result was considerable numbness in the second and third division territories, with partial numbness in the area of the first division. No masticatory weakness was observed. She was discharged home next day.
Six weeks later she was comfortable and free from pain. Corneal reflexes were equal to blowing; no longer was there any detectable sensory loss in the first or second division. In the area of the third division, tickle sense was diminished, and pin-prick and the sensation of 'scratch' with a pin were both reduced although the nature of the stimulus could be identified. Sensory loss was category A in Table I. One year later the patient remained free from pain.

A man, aged 76, had had left trigeminal neuralgia (mainly second division) for five and a half years. For 18 months the pain was relieved with mephenesin carbamate or with Gower's mixture. The pain then recurred and became intolerable. Two injections were necessary. At the first, when the needle passed through the lateral third of the foramen ovale, an injection of $0.60 \mathrm{ml}$. of phenol 1:30 in glycerine produced no detectable effect. Next day the injection was repeated with the needle directed more medially; cerebrospinal fluid escaped when the needle was $2 \mathrm{~mm}$. anterior to the clivus. Phenol 1:30 was again used; $0.15 \mathrm{ml}$. was injected and then, because there was already evidence of depressed conduction in the fibres of the first division, the needle was withdrawn $3 \mathrm{~mm}$. and a further $0.10 \mathrm{ml}$. was injected. The final result was a diminished left corneal reflex ando slight hypalgesia in the first division; finger touch was just appreciated on the cheek and lower lip; pin-prick was not recognized in the second division and was onl inconstantly recognized in the third division; there wå weakness of the left masseter.

Six months later he was free from pain. He was aware of stiffness of the left angle of his mouth, and of a numter feeling in the tongue and the left side of the palate There was no tendency for food or drink to escape urfo noticed from the left side of his mouth. He had noticed $\%$ no disturbance of his sense of taste. On re-examination, sensory functions in the first division were now normal; on the left cheek pin-prick was slightly diminished, and on the left upper and lower lips a pin felt like a lead pencil. The threshold to cotton wool was raised in the left second and third divisions; this increase in threshold was greatest on the lower lip and least on the cheek. Trigeminal motor functions were normal, sensory loss was category B in Table I.

A woman, aged 55, had left trigeminal neuralgia for five years involving mainly the third division with some pain in the second division. (An alcohol injection at the foramen ovale had been given 18 months previously. Before the phenol injection there was a slight sensory deficit in the left second and third trigeminal divisions.)

At injection, when the needle point was judged radiologically to be in the correct position blood flowed freely; the flow ceased when the needle was withdrawn $4 \mathrm{~mm}$. Phenol 1:20 in glycerine was injected; $0.15 \mathrm{ml}$. followed by $0.20 \mathrm{ml}$. The needle was then withdrawn $2 \mathrm{~mm}$. and a final injection of $0.10 \mathrm{ml}$. of phenol was made. Examination next day showed the corneal response brisk to blowing, but there was a change in quality of tactile sense on the forehead, with complete analgesia in the left second and third divisions; in these areas gentle 
rubbing with a finger felt like a feather. No masticatory weakness was observed.

Four months later, all first division functions appeared normal. Tickle sense was reduced in the left upper and lower lips, the threshold for touch was considerably raised in the left second and third division territories, whilst in these areas a pin-prick felt like a touch with a lead pencil. Sensory loss was category B in Table I.

Sixteen months later an acute recurrence of pain led to a second phenol injection. If, and when, the pain recurs it is envisaged that a trigeminal root section will be performed.

A woman, aged 69, had right second and third division neuralgia for two and a half years. She was originally largely relieved by an alcohol injection of the infraorbital nerve. When the pain recurred a phenol injection was given. At injection, the needle traversed the medial third of the foramen ovale and the point lay exactly opposite to the clivus, and was possibly rather more inferior than is usual within Meckel's cave. With the patient erect $0.20 \mathrm{ml}$. phenol 1:20 in glycerine was injected. Within 30 seconds a complete right trigeminal anaesthesia and analgesia had developed. A Perspex side-shield was fitted to her spectacles.

Six weeks later, the right eye was healthy and uninflamed although it felt uncomfortable, as though there was a small piece of grit beneath the lids. The corneal reflex was completely absent to blowing, and there was a complete trigeminal sensory lesion. The right masseter muscle appeared slightly weakened, but the right pterygoid was normal. Eight months after the injection the pain remained fully controlled, and she continued to find the numbness tolerable.

There was only one other case of a complete sensory lesion in the whole series (category $\mathrm{C}$ in Table I).

\section{STUDIES ON THE DISTRIBUTION OF MYODIL}

In order to determine the cubic capacity of Meckel's cave with the trigeminal ganglion, posterior root, and injection needle all in situ, preliminary studies were undertaken in the necropsy room using Indian ink. In a short series, it appeared that ink might overflow from the mouth of Meckel's cave with volumes varying between $0.05 \mathrm{ml}$. and $0.15 \mathrm{ml}$. Using the somewhat more viscous Myodil and employing radiography to detect its presence, the cave was shown to be overflowing after injecting $0.2 \mathrm{ml}$. (Fig. 5). However, these studies were relatively crude and were imprecise in the sense that the skull was open and it proved impossible to obtain radiographs with a cadaver in a posture comparable to that usually adopted by the patient (Fig. 4).

From studies performed in vivo, it appears that there are three common patterns of distribution of injected Myodil. First, the Myodil may follow what

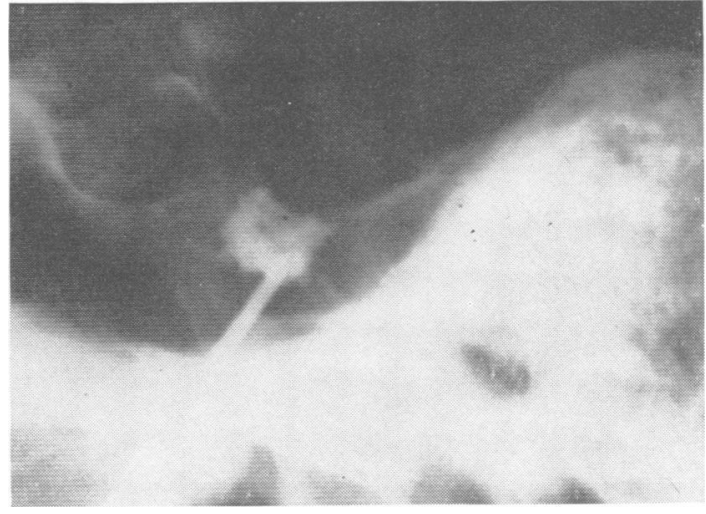

FIG. 5. True lateral radiograph obtained as in Figure 1. In this instance $0.2 \mathrm{ml}$. Myodil has been injected. A further film exposed a few minutes later showed that some of the Myodil had begun to escape into the posterior cranial fossa.

appears, at least in its anterior part, to be the course of the trigeminal posterior root. Under these circumstances, the injection mass has presumably been released among the posterior root fibres and has 'tracked' along them, or else it has adhered to the root due perhaps to some vagary of surface tension. Secondly, the Myodil may create a pattern similar to that in Figure 5. Under these circumstances it has presumably been injected either into the substance of the ganglion itself or else into the extra-arachnoid plane within Meckel's cave. From this situation a small quantity of the Myodil may escape and outline the anterior portion of the posterior trigeminal root within the posterior fossa. Thirdly, the Myodil may escape from Meckel's cave in the subarachnoid plane and drop out of the skull into the spinal canal. Figure 6 shows that small volumes injected into Meckel's cave may spread widely within the skull. In this man, aged 44 (no. 62/224), $0 \cdot 1 \mathrm{ml}$. Myodil was injected (Fig. 6a) after $0.4 \mathrm{ml}$. of phenol 1:30 in glycerine. Subsequently, a further $0.1 \mathrm{ml}$. Myodil was injected (Fig. 6b). Four hours later another radiograph revealed that a surprisingly large amount of Myodil was still lodged within the skull. The second type of distribution is shown in Figure 7. These radiographs concern a woman of 60 (no. 60/ 999), in whom a total of $0.2 \mathrm{ml}$. of Myodil was injected after $0.30 \mathrm{ml}$. phenol solution. A fairly dense 'blob' of Myodil is seen and it appears to be largely confined to the region of Meckel's cave. Figure 8 illustrates the third type of distribution. This concerns a man of 51 (no. 61/916) in whom $0 \cdot 1$ $\mathrm{ml}$. Myodil was injected after a total of $0.55 \mathrm{ml}$. phenol in glycerine. The lateral radiograph shows a few scattered drops of Myodil but not enough to 
FIG. 6. Lateral radiographs of the skull after the injection of Myodil in vivo. No cerebrospinal fluid escaped from the needle.

A To show appearance after the injection of $0.1 \mathrm{ml}$. Myodil.

B To show appearance after a total of $0.2 \mathrm{ml}$. Myodil had been injected.
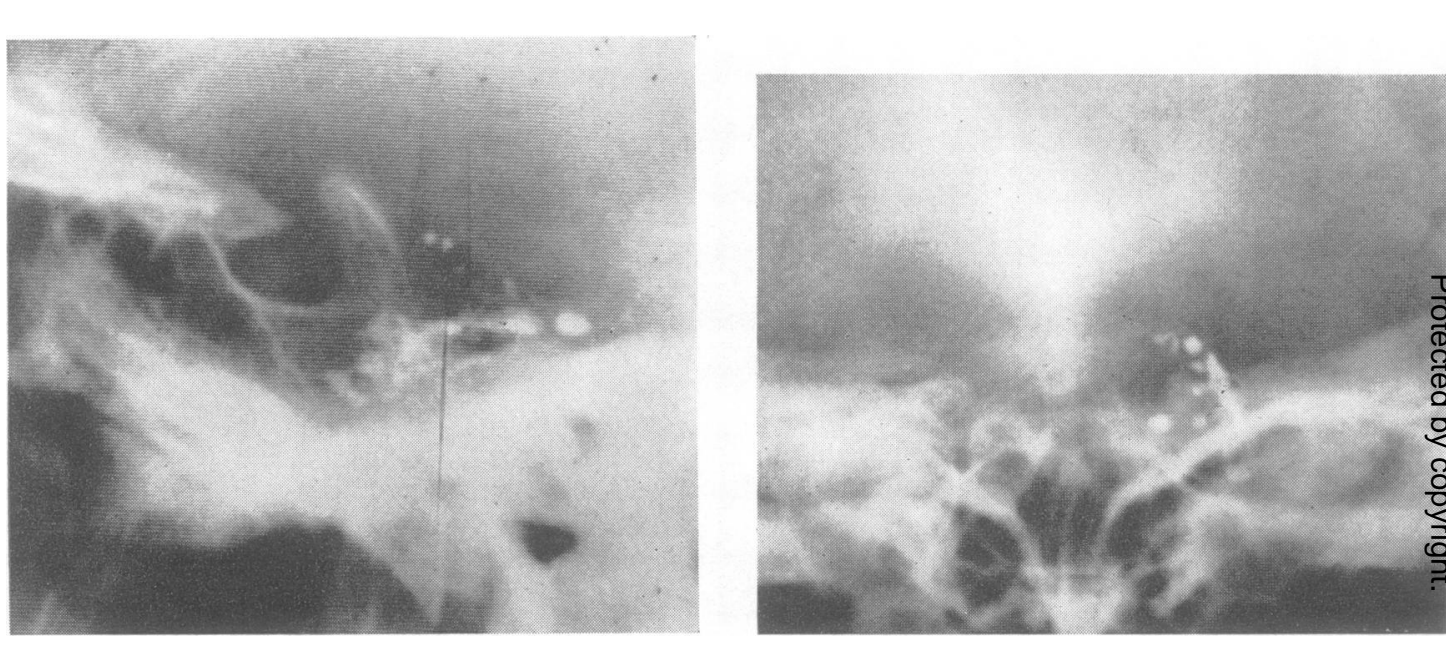

FIG. 7. Patient supine.

Left Lateral radiograph obtained after injection of $0.2 \mathrm{ml}$. Myodil.

Right Sagittal projection demonstrating position of the Myodil.

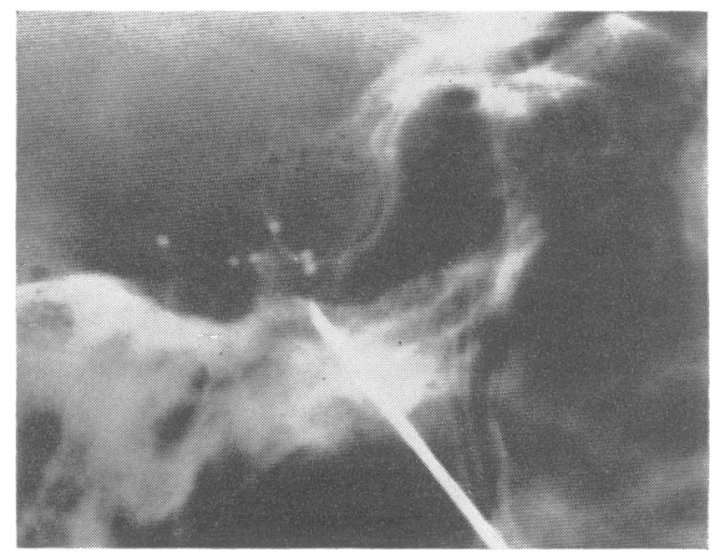

FIG. 8. Patient erect. Lateral radiograph of skull after the injection of $0.1 \mathrm{ml}$. of Myodil. Some of the injected Myodil must have escaped in the cerebrospinal fluid pathways. 
correspond with a volume of $0 \cdot 1 \mathrm{ml}$. The main portion of the injected Myodil has evidently escaped in the cerebrospinal fluid and must now lie inferior to the area shown in the radiograph.

\section{DISCUSSION}

It is not my purpose to argue the relative merits of injection versus operation in the treatment of trigeminal neuralgia. That there is a place for injection treatment cannot seriously be denied by anyone who reflects that even the safest surgery carries a certain mortality rate, e.g., $3 \cdot 2 \%$ (Burmeister, 1960). Moreover many of the patients requiring trigeminal injection are elderly and may be arteriosclerotic and hypertensive. In consequence, some degree of hemiparesis or, when operation is beneath the dominant temporal lobe, some dysphasia may be present postoperatively. In the relatively small series of cases reported here there was no mortality and the morbidity has been confined to one very transient abducent paresis, and to occasional post-injection herpes. This kind of result, which is by no means unique (e.g., Harris, 1940; Penman, 1949; Jaeger, 1959), is the justification for treatment by injection.

Since Taarnhøj (1952) applied controlled trauma to the trigeminal posterior root as an alternative to root section in the treatment of neuralgia, a number of variants of his technique have developed, e.g., by Stender (1954) and by Shelden, Pudenz, Freshwater, and Crue (1955). That these methods give excellent results is clear from reports such as that of Hamby (1960). The aim of applying controlled trauma to the posterior trigeminal root can obviously be achieved either mechanically, physically, or chemically.

Jelašić in 1959 reported an ingenious and promising method for applying moderate trauma to the trigeminal ganglion by means of a blunt instrument passed through the foramen ovale. His instrument was inserted under general anaesthesia after an incision had been made in the mucous membrane of the mouth. It should be possible to devise an instrument which could be introduced percutaneously via a needle or cannula and which could cause mechanical damage to the trigeminal ganglia or root. To the best of my knowledge this has not been achieved to date so that, with the exception of Jelašić's manoeuvre, deliberate trauma has always been applied by one or other of the open operative techniques.

Physical trauma by the injection of hot water has been the method adopted by Jaeger (1957). As in the series described here, Jaeger did nothing to prevent cerebrospinal fluid from escaping from his needle; he also did not aim at causing complete trigeminal anaesthesia. However, it seems probable from his descriptions that hot water injections cause more sensory loss than do phenol injections. Certainly the motor loss was greater, for Jaeger reported partial or complete masticatory paralysis in every patient. In both Jaeger's and my own groups of patients full functional recovery of motor activity returned within three or four months.

Another technique of injection which was successful in avoiding a profound sensory loss has been recorded (Ecker and Perl, 1958; Perl and Ecker, 1959). Ecker and Perl used absolute alcohol, but in almost every case not more than $0.30 \mathrm{ml}$. was required. The injections were made in increments of $0.05 \mathrm{ml}$. and the object was to control pain with the minimum possible sensory loss. Ecker and Perl used very precise methods for placing the needle in position and they devised an aiming-grid modified from that described by Penman (1953). It is interesting that Härtel (1935) in his later writings reported the reduction of the volume of alcohol injected, from the 0.5 to $1.0 \mathrm{ml}$. which he originally recommended, down to 0.1 to $0.3 \mathrm{ml}$. Härtel also recorded that of those patients with total sensory loss only $4 \%$ developed recurrent pain (in one the recurrence appeared after an interval of 14 years), whilst of those with partial sensory loss $70 \%$ recurred at intervals varying between six months and four years. My own series with a mean follow-up period of only $12 \frac{1}{2}$ months cannot be fully assessed regarding liability to recurrence. However, in view of the results so far obtained it seems worthwhile to attempt to preserve sensation even at the risk of a proportion of these patients developing recurrent pain. The injections are relatively simple and on the occasions where late re-injections have been necessary, there have been no additional technical difficulties which might be ascribed to the earlier injections.

Perhaps, by more precise techniques for the introduction of the needle it would be possible to avoid the immediate re-injections which were necessary in $18 \%$ of the present series. However, the aim has been to develop the simplest possible technique which was safe enough to have the widest possible application. In view of the success of the method to date in the relief of pain the radiological control described in the text is not currently being modified.

When Maher (1955) introduced phenol for the control of pain in cancer he was in ignorance of any previous use of this agent for similar purposes. Likewise, when extrapolating from the work of Maher, I was unaware that phenol had been used before for trigeminal injections. However, rarely is it possible justly to claim a procedure as something entirely new. Thus, it is a pleasure to record that when Putnam and Hampton described a technique 
for performing trigeminal ganglion injections under radiological control in 1936 they wrote: 'The substance which we prefer in most cases is $5 \%$ phenol, which has the advantage . . . that extremely small amounts-0.5 cc. or less-are effective'. Doctor Tracy Putnam (1962) in answer to a recent query has stated that the phenol was in aqueous solution. He reported that he did not continue with this method because he left Boston soon after this paper was published and ceased to be in a position to collaborate with Doctor Hampton.

It will be no surprise to learn that others have injected radio-opaque materials within Meckel's cave. Sicard (1924) reported three patients in whom after completion of an alcohol injection he had inserted $1 \mathrm{ml}$. of Lipiodol. No radiographs were reproduced in his paper and the text did not describe the results in any detail. Penman (1953) employed a mixture of 4 parts by volume of absolute ethyl alcohol and 1 part of Myodil. Penman's description of his successful injections sounds very similar to that illustrated in Figure 7. Penman observed that the injection mass might escape into the posterior fossa and felt that when this happened, even though there was transient trigeminal anaesthesia, there would not be a lasting successful result. No doubt there are significant differences in the behaviour of alcohol and phenol, but $I$ would agree that the most consistently favourable results seem to occur with injections as in Figure 7 . In the present series Myodil has not been injected mixed with phenol, because the routine use of a radio-opaque agent has not seemed necessary.

If injections are to be made into the subarachnoid space within Meckel's cave it is important to be aware that it has a very small capacity. As long ago as 1926, Harris had shown that in the cadaver injection of $1.0 \mathrm{ml}$. of methylene blue at the foramen ovale would sometimes stain the anterior surface of the pons or even the opposite cavernous sinus. No doubt the ocular motor pareses (usually transient) which are not infrequently associated with intraganglionic injections of alcohol are caused by alcohol escaping from the mouth of Meckel's cave. Presumably these effects are almost never seen with phenol dissolved in glycerine because this is a heavy medium and such of it as may escape from within Meckel's cave cannot bathe the third, fourth, or sixth cranial nerves.

However incompletely successful are the results recorded in this paper, they add to the existing evidence that in the control of trigeminal neuralgia excellent, or at least satisfactory, results may be obtained without complete trigeminal anaesthesia. $\bar{z}$ No doubt the methods described here can and will $\stackrel{\mathbb{C}}{=}$ be improved upon. This is no enduring or final report, but if it serves to stimulate others into perfecting methods which control pain while preserving sensation, it will have served its purpose.

\section{SUMMARY}

A technique for the intracranial injection of the trigeminal ganglion and posterior root using phenol in glycerine is described. A simple method of radiographic control is routinely employed.

A total of 37 patients have been treated, of whom 32 had true trigeminal neuralgia.

Phenol usually causes no more than a partial sensory loss; it may be regarded as causing $a \vec{\circ}$ chemical 'gangliolysis' or 'neuronolysis'. The method appears relatively simple, safe, and remarkably free $\vec{\omega}$ from complications, and the control of pain has been entirely satisfactory.

Some observations are added on the distribution of material injected within Meckel's cave. These O observations emphasize the desirability of limiting $\dot{\omega}$ strictly the volume of the material injected.

I should like to express gratitude to my senior colleagu James Hardman, F.R.C.S., for the fact that he taught re to use the Härtel technique.

I am also much indebted to the following radiographexs for their interest and assistance in studying the position क of the needle and of the injected 'Myodil': Mr. W. H Coombes, Miss J. M. Osborne, Mrs. N. A. De La Haye, and Mrs. K. Byron Thomson.

\section{REFERENCES}

Burmeister, H. (1960). Langenbecks Arch. klin. Chir., 295, 175.

Ecker, A., and Perl, T. (1958). Neurology (Minneap.), 8, 461.

Hamby, W. B. (1960). J. Neurosurg., 17, 1039.

Harris, W. (1926), Neuritis and Neuralgia, Oxford University Press, $\vec{\overrightarrow{ }}$ London. (1940). Brain, 63, 209.

Härtel, F. (1912). Langenbecks Arch. klin. Chir., 100, 193.

- (1935). Dtsch. med. Wschr., 61, 1069.

Jaeger, R. (1957). A.M.A. Arch. Neurol., 77, 1. (1959). J. Neurosurg., 16, 656.

Jelašic, F. (1959). Acta neurochir. (Wien), 7, 440.

King, R. B. (1958). J. Neurosurg., 15, 290.

Maher, R. M. (1955). Lancet, 1, 18.

Penman, J. (1949). Ibid., 2, 268.

- (1953). Ibid., 1, 760.

Perl, T., and Ecker, A. (1959). Amer. J. Roentgenol., 82, 830.

Putnam, T. J., and Hampton, A. O. (1936). Arch. Neurol. Psychiat. (Chicago)., 35, 92.

Shelden, C. H., Pudenz, R. H., Freshwater, D. B., and Crue, B. L. (1955). J. Neurosurg., 12, 123.

Sicard, J. H. (1924). Rev. neurol., 31 (1), 237.

Stender, A. (1954). J. Neurosurg., 11, 333.

Taarnhøj, P. (1952). Ibid., 9, 288. 